\title{
Influence of Preservation Solutions and Bile on a Human Bile Duct Epithelium Cell Line: An In-Vitro Study
}

\author{
Philipp Stiegler ${ }^{1}$, Ursula Mayrhauser ${ }^{1}$, Sonja Koestenbauer ${ }^{1}$, Bettina Leber ${ }^{1}$, Katja Konrad ${ }^{1}$, \\ Florian Iberer $^{1}$, Karlheinz Tscheliessnigg ${ }^{1}$, Vanessa Stadlbauer ${ }^{2}$ \\ ${ }^{1}$ Division of Surgery, Department for Transplantation Surgery, Medical University Graz, Graz, Austria \\ ${ }^{2}$ Division of Internal Medicine, Department of Gastroenterology and Hepatology, Medical University Graz, Graz, Austria \\ Email: philipp.stiegler@medunigraz.at, u.mayrhauser@gmail.com, so.ko@gmx.a, bettina.leber@medunigraz.at, \\ karja.konrad@medunigraz.at, florian.iberer@medunigraz.at, karlheinz.tscheliessnigg@medunigraz.at, \\ vanessa.stadlbauer@medunigraz.at
}

Received September 28, 2012; revised November 1, 2012; accepted November 9, 2012

\begin{abstract}
Introduction: Bile duct complications are common after liver transplantation. The impact of preservation solution is unclear. Aim: We investigated the impact of different preservation solutions with and without diluted bile on a human biliary tract carcinoma cell line. Methods: The human biliary tree carcinoma cell line SK-ChA-1 was cultured with either medium or University of Wisconsin solution (UW), histidine-tryptophane-ketoglutarate (HTK) solution, Celsior or physiological saline for $6 \mathrm{~h}, 10 \mathrm{~h}$ or $12 \mathrm{~h}$ at $6^{\circ} \mathrm{C}-8^{\circ} \mathrm{C}$ and metabolic activity was measured by a MTS (3-(4,5-dimethylthiazol-2-yl)-5-(3-carboxymethoxyphenyl)-2-(4-sulfophenyl)-2H-tetrazolium)-test immediately, after $12 \mathrm{~h}$ or $24 \mathrm{~h}$. Cells were also incubated in combination with diluted porcine bile. Results: Immediately after cold storage of $6 \mathrm{~h}$ HTK and UW decreased metabolic activity whereas Celsior increased metabolic activity after $10 \mathrm{~h}$ or $12 \mathrm{~h}$ of cold ischemia. After $12 \mathrm{~h}$ or $24 \mathrm{~h}$ no major differences were found any more. Incubation with bile in combination with HTK, Celsior or $\mathrm{NaCl}$ decreased metabolic activity, whereas UW abolished this effect. Conclusion: On a cellular level differences between preservation solutions were found, especially in combination with bile. Further studies are warranted to determine whether this results in clinically significant differences in biliary complications.
\end{abstract}

Keywords: Organ Preservation; Liver Transplantation; Bile Duct Epithelium; In Vitro

\section{Introduction}

Liver transplantation (LTX) is the therapy of choice for many end stage liver diseases [1]. Due to technical advances [2] and new immunosuppressive regimens $[3,4]$ long term survival of LTX patients nowadays reaches up to $70 \%$ over 10 years [5]. However, biliary complications, such as ischemic complications, technical complications, non-anastomotic strictures or infectious complications occur in $5 \%-25 \%$ and are a common cause of morbidity after LTX [6]. Besides surgical problems, bile duct damage during ischemia and reperfusion or bile salt cytotoxicity plays a major role [7-9].

University of Wisconsin (UW) and histidine-tryptophan-ketoglutarate (HTK) are the most commonly used preservation solution for cadaveric liver transplantation [10]. Celsior is mainly used in cardiac preservation, but is also supposed to be used for preservation of abdominal organs. Several studies compared the different solutions, however, no clear superiority has been shown [11-19]. The influence of bile on bile duct damage during organ preservation is poorly investigated.
The aim of this study was therefore to investigate the protective effect of different preservation solutions on a human biliary tract carcinoma cell line. Furthermore, the impact of different preservation solutions in combination with variable concentrations of bile was tested for their preservation capacity.

\section{Material and Methods}

\subsection{Cell Culture Experiments}

The human biliary tract carcinoma cell line SK-ChA-1 [Donation from Prof. Knuth (University of Zurich, Switzerland [20])] was cultured at $37^{\circ} \mathrm{C}$ in RPMI 1640 with GlutaMAX (Invitrogen, Austria) containing 10\% fetal calf serum (PAA, Austria), 1\% MEM non essential amino acids (Invitrogen, Austria), 1\% L-gluatmine (Invitrogen, Austria) and 1\% penicillin/streptomycin (PAA, Austria) in a humified atmosphere $\left(5 \% \mathrm{CO}_{2}\right)$. After overnight culture $\left(7 \times 10^{5}\right.$ cells $\left./ \mathrm{ml}\right)$ in 24 well plates, cell culture medium was replaced by either UW $\left(\mathrm{ViaSpan}^{\circledR}\right.$, Austria), HTK (Custodiol-Perfusionsloesung, Diagnosia, 
Austria), Celsior (Genzyme, Netherlands) or $0.9 \% \mathrm{NaCl}$ ( $0.9 \%$ physiological saline; Fresenius Kabi, Austria). Cell culture medium was used as control. After adding 1 $\mathrm{ml}$ of the different preservation solutions, cells were incubated for 6,10 and 12 hours at $6^{\circ} \mathrm{C}-8^{\circ} \mathrm{C}$ mimicking cold ischemia time. Thereafter preservation solutions were replaced by $1 \mathrm{ml}$ cell culture medium and cells were cultivated at $37^{\circ} \mathrm{C}$. Metabolic activity of SK-ChA-1 cells was tested immediately as well as after 12 and 24 hours of culture at $37^{\circ} \mathrm{C}$ as described below.

For the study of bile toxicity, medium was replaced by preservation solutions UW, HTK, Celsior and $\mathrm{NaCl}$ containing different amounts of gallbladder bile (no bile, $1: 2000,1: 100,1: 50,1: 33$ and 1:25) from pigs and incubated for 6 hours at $6^{\circ} \mathrm{C}-8^{\circ} \mathrm{C}$ in order to simulate cold preservation of a bile duct without flushing. Metabolic activity was tested immediately after ischemia in different perfusion solutions.

\subsection{Metabolic Activity}

MTS (3-(4,5-dimethylthiazol-2-yl)-5-(3-carboxymethoxyphenyl)-2-(4-sulfophenyl)-2H-tetrazolium)-test (CellTiter $96^{\circledR}$ AQueous One Solution Cell Proliferation Assay, Promega, Austria) was used exactly as described by the manufacturer. Briefly, the preservation solutions were replaced by $1 \mathrm{ml}$ medium and spiked with $200 \mu \mathrm{MTS}$ reagent. After 2 hours incubation with the MTS reagent at $37^{\circ} \mathrm{C} 3 \times 120 \mu \mathrm{l}$ of the solution were transferred into a 96 well plate and the absorbance was measured at wavelengths of $490 \mathrm{~nm}$ and $650 \mathrm{~nm}$ using the SpectraMax Plus 384 (Molecular Devices, USA). The difference be- tween the two wavelengths was determined.

\subsection{Statistical Analysis}

An average value from $2 \times 3$ different wells from each approach was calculated and the experiments were repeated 5 times. For the analyses either MTS values or normalised metabolic activity is used. Statistical analyses and graphs are created with GraphPad Prism version 5.00 software for Windows (GraphPad Software, San Diego California USA, www.graphpad.com). Comparison of the data is performed using one-way ANOVA. A p < 0.05 is considered to be statistically significant.

\section{Results}

\subsection{Impact of Different Preservation Solutions on the Metabolic Activity of the Human Biliary Tract Carcinoma Cell Line SK-ChA-1}

Immediately after cold storage for 6,10 or 12 hours, differences in metabolic activity of cultured human biliary tree carcinoma cells were found. $6 \mathrm{~h}$ of cold storage with UW ( $\mathrm{p}<0.05)$, and HTK ( $<<0.001)$ significantly decreased metabolic activity compared to medium. 10 and 12 hours of cold storage with Celsior $(p<0.001)$ significantly increased metabolic activity (Figure 1).

12 hours later these differences were diminished, only UW after $6 \mathrm{~h}$ of cold storage showed a significantly lower metabolic activity $(\mathrm{p}<0.05)$ compared to medium. After $24 \mathrm{~h}$ no changes in metabolic activity between the differentially treated cells could be found (Table 1).
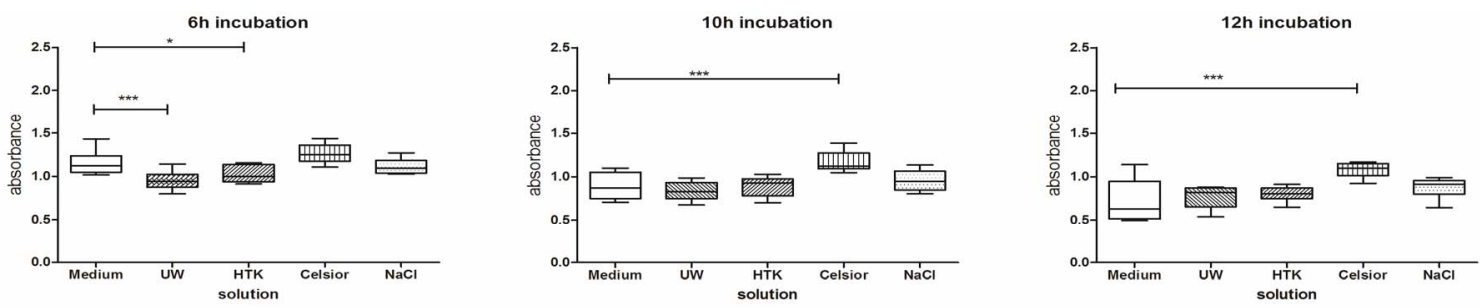

Figure 1. Metabolic activity of SK-ChA-1 after exposure to different preservation solutions immediately after cold storage. SK-ChA-1 cells were incubated for 6,10 and 12 hours at $6^{\circ} \mathrm{C}-8^{\circ} \mathrm{C}$ with $\mathrm{UW}$, HTK, Celsior or $0.9 \% \mathrm{NaCl}$ and metabolic activity was measured. ${ }^{*} \mathrm{p}<0.05,{ }^{* *} \mathrm{p}<0.01,{ }^{* * *} \mathrm{p}<0.001$.

Table 1. Metabolic activity of SK-ChA-1 after exposure to different preservation solutions $12 \mathrm{~h}$ and $24 \mathrm{~h}$ after cold storage for $6 \mathrm{~h}, 10 \mathrm{~h}$ or $12 \mathrm{~h}$.

\begin{tabular}{|c|c|c|c|c|c|c|}
\hline & $\begin{array}{c}\text { ours after } 6 \mathrm{~h} \\
\text { storage }\end{array}$ & $\begin{array}{l}\text { urs after } 6 \mathrm{~h} \\
\text { storage }\end{array}$ & $\begin{array}{c}\text { urs after } 101 \\
\text { storage }\end{array}$ & $\begin{array}{c}\text { urs after } 10 \mathrm{~h} \\
\text { storage }\end{array}$ & $\begin{array}{c}\text { urs after } 121 \\
\text { storage }\end{array}$ & $\begin{array}{l}\text { urs after } 12 \mathrm{~h} \text { cold } \\
\text { storage }\end{array}$ \\
\hline Medium & $1.27 \pm 0.08$ & $1.55 \pm 0.27$ & $1.00 \pm 0.24$ & $1.31 \pm 0.23$ & $0.88 \pm 0.21$ & $1.16 \pm 0.24$ \\
\hline HTK & $1.23 \pm 0.10$ & $1.51 \pm 0.15$ & $1.14 \pm 0.13$ & $1.55 \pm 0.17$ & $1.10 \pm 0.10$ & $1.54 \pm 0.21$ \\
\hline $\mathrm{NaCl}$ & $1.14 \pm 0.05$ & $1.51 \pm 0.21$ & $1.03 \pm 0.16$ & $1.41 \pm 0.25$ & $0.96 \pm 0.05$ & $1.37 \pm 0.26$ \\
\hline Celsior & $1.21 \pm 0.05$ & $1.55 \pm 0.18$ & $1.13 \pm 0.13$ & $1.44 \pm 0.20$ & $1.01 \pm 0.06$ & $1.42 \pm 0.19$ \\
\hline UW & $1.10 \pm 0.12^{*}$ & $1.46 \pm 0.29$ & $0.94 \pm 0.25$ & $1.25 \pm 0.36$ & $0.90 \pm 0.11$ & $1.34 \pm 0.36$ \\
\hline
\end{tabular}

${ }^{*} \mathrm{p}<0.05$ compared to medium. 


\subsection{Impact of Bile in Combination with Different Preservation Solutions on the Metabolic Activity of the Human Biliary Tract Carcinoma Cell Line SK-ChA-1}

When cells were incubated with decreasing bile dilutions and one of the preservation solutions and their metabolic activity was normalized to the preservation solution alone, we found that with HTK, Celsior and $0.9 \% \mathrm{NaCl}$ metabolic activity significantly decreased at decreasing bile dilutions $(1: 50,1: 33,1: 25, \mathrm{p}<0.01$ and $\mathrm{p}<0.001$, Figure 2). With UW no decrease in metabolic activity with increasing bile concentrations was seen.

\section{Discussion}

Biliary complications still remain a problem in LTX [21]. Several studies investigated the differences between UW HTK and CS in liver preservation, but no significant differences were found in preventing biliary complications (reviewed in [22]). Therefore, the aim of this study was to evaluate the influence of different preservation solutions on a cellular level with or without addition of porcine bile on the biliary tract carcinoma cell line SK-ChA1 in terms of metabolic activity.

Cold storage temporarily changed metabolic activity of SK-ChA-1 cells stored in HTK, UW or $0.9 \% \mathrm{NaCl}$ but increased metabolic activity of cells stored in Celsior. However this effect was completely lost after $24 \mathrm{~h}$. Treatment with porcine bile at higher concentrations impaired metabolic activity of SK-ChA-1 cells but UW was able to abolish this effect.

These results of our cold storage model are not sur-

UW
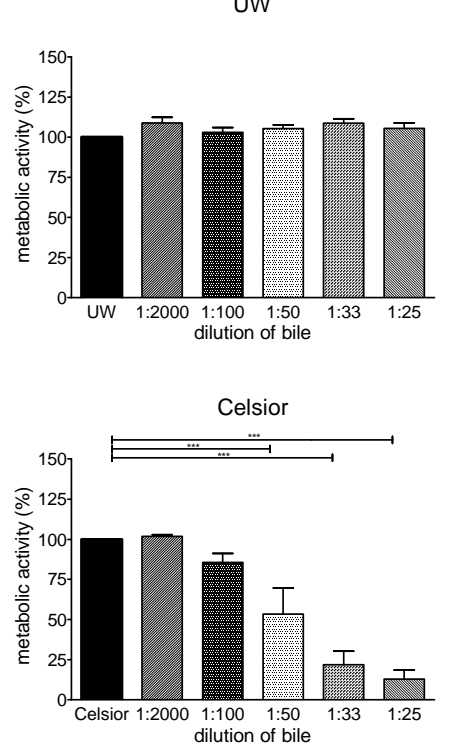

prising since none of the common preservation solutions is superior in protecting biliary epithelial cells from cold storage and reperfusion injury. Biliary complications after LTX are also clinically not correlated with a prolonged cold ischemia time [23]. Recent studies showed that livers from donation after cardiac death can be successfully used without a major increase in biliary complications, indicating that even warm ischemia does not significantly increase biliary complications [24].

Our study also shows that UW is superior to other solutions in preserving SK-ChA-1metabolic activity in the presence of bile. This finding is surprising since UW has a relatively high viscosity that has been hypothesized to cause insufficient sinusoid perfusion or induce microcirculatory disturbances, which might negatively impact on LTX outcome [25]. UW is well known for its beneficial effects on hepatic nutrition; however because of the relatively high viscosity it might cause insufficient sinusoid perfusion or induce microcirculatory disturbances, which negatively impact on LTX outcome [26]. Several alternative preservation solutions have been developed over the years, including histidine-tryptophan-ketoglutarate (HTK) and Celsior. HTK has shown to guarantee an equal preservation for hepatocytes and due to its reduced viscosity as compared to UW solution it has been hypothesised to be more protective against the development of intrahepatic biliary complications [10,25-29]. All preservation solutions contain specific components to prevent cellular damage, caused by warm ischemia, cold preservation and reperfusion [30]. These properties obviate cell swelling, reduce the oxidative injury via radical scavengers andcontain adenosine (UW), $\alpha$-ketoglutarate (HTK) or glu-
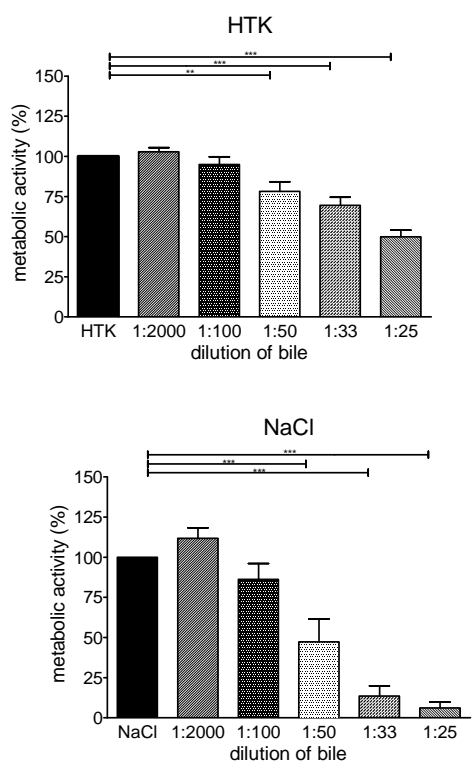

Figure 2. Normalized metabolic activity of SK-ChA-1 after exposure to different preservation solutions and different dilutions of bile SK-ChA-1 cells were incubated with UW, HTK, Celsior and NaCl and different dilutions of porcine bile. Metabolic activity was measured and normalized to metabolic activity of cells in medium $(100 \%) .{ }^{*} p<0.05,{ }^{* *} p<0.01,{ }^{* * *}$ p $<0.001$. 
tamic acid (Celsior) to maintain the intracellular energy level $[13,31]$. Clinically, none of the solutions has been shown to be convincingly superior to the other one [10$19,26,27,32]$.

Bile is known to induce cell membrane damage because of their detergent properties [33]. Bile salts induce necrosis or apoptosis, but under physiological conditions several cytoprotective mechanisms are in place to protect biliary epithelium from damage [34]. Cold ischemia however can aggravate cellular damage [35].

Our model has several limitations: First, a biliary tree carcinoma cell line might not be completely comparable to normal human cholangiocytes concerning response to ischemia and other stress conditions. Second, we have not assessed whether the cell line shows differences to normal cholangiocytes with regards to the measurement of viability used in this study. Third, we used porcine bile, which may cause cross species bile acid interactions.

In conclusion we could show that there are no long lasting differences between preservation solutions in metabolic activity of biliary epithelium cells. Furthermore we observed UW was able to prevent bile toxicity as measured by metabolic activity of a biliary epithelium cell line. Further studies are warranted to confirm the positive effect of UW solution on biliary epithelium in vivo and to study whether flushing the extrahepatic bile duct during liver transplantation with UW might be able to prevent biliary complications.

\section{REFERENCES}

[1] S. A. Alqahtani, "Update in Liver Transplantation," Current Opinion in Gastroenterology, Vol. 28, No. 3, 2012, pp. 230-238. doi:10.1097/MOG.0b013e3283527f16

[2] O. Abbasoglu, "Liver Transplantation: Yesterday, Today and Tomorrow," World Journal of Gastroenterology, Vol. 14, No. 20, 2008, pp. 3117-3122. doi:10.3748/wjg. 14.3117

[3] G. A. Bishop, F. L. Ierino, A. F. Sharland, et al., "Approaching the Promise of Operational Tolerance in Clinical Transplantation," Transplantation, Vol. 91, No. 10, 2011, pp. 1065-1074. doi:10.1097/TP.0b013e318215e742

[4] A. A. Schnitzbauer, H. J. Schlitt and E. K. Geissler, "Influence of Immunosuppressive Drugs on the Recurrence of Hepatocellular Carcinoma after Liver Transplantation: A Gap between Basic Science and Clinical Evidence," Transplantation, Vol. 91, No. 11, 2011, pp. 1173-1176. doi:10.1097/TP.0b013e318215e72b

[5] F. Aberg, H. Isoniemi and K. Hockerstedt, "Long-Term Results of Liver Transplantation," Scandinavian Journal of Surgery: SJS: Official Organ for the Finnish Surgical Society and the Scandinavian Surgical Society, Vol. 100, No. 1, 2011, pp. 14-21.

[6] D. G. Buck and A. B. Zajko, "Biliary Complications after
Orthotopic Liver Transplantation," Techniques in Vascular and Interventional Radiology, Vol. 11, No. 1, 2008, pp. 51-59. doi:10.1053/j.tvir.2008.05.006

[7] S. C. Chan and S. T. Fan, "Biliary Complications in Liver Transplantation," Hepatology International, Vol. 2, No. 4, 2008, pp. 399-404. doi:10.1007/s12072-008-9092-Z

[8] T. Hampe, A. Dogan, J. Encke, et al., "Biliary Complications after Liver Transplantation," Clinical Transplantation, Vol. 20, No. 17, 2006, pp. 93-96.

[9] B. Y. Tung and M. B. Kimmey, "Biliary Complications of Orthotopic Liver Transplantation," Digestive Diseases, Vol. 17, No. 3, 1999, pp. 133-144. doi:10.1159/000016918

[10] F. Rayya, J. Harms, A. P. Martin, et al., "Comparison of Histidine-Tryptophan-Ketoglutarate Solution and University of Wisconsin Solution in Adult Liver Transplantation," Transplantation Proceedings, Vol. 40, No. 4, 2008, pp. 891-894. doi:10.1016/j.transproceed.2008.03.044

[11] F. A. Garcia-Gil, J. Arenas, A. Guemes, et al., "Preservation of the Liver Graft with Celsior Solution," Transplantation Proceedings, Vol. 38, No. 8, 2006, pp. 2385-2388. doi:10.1016/j.transproceed.2006.08.032

[12] F. A. Garcia-Gil, M. T. Serrano, L. Fuentes-Broto, et al., "Celsior versus University of Wisconsin Preserving Solutions for Liver Transplantation: Postreperfusion Syndrome and Outcome of a 5-Year Prospective Randomized Controlled Study," World Journal of Surgery, Vol. 35, No. 7, 2011, pp. 1598-1607. doi:10.1007/s00268-011-1078-7

[13] H. Janssen, P. H. Janssen and C. E. Broelsch, "UW Is Superior to Celsior and HTK in the Protection of Human Liver Endothelial Cells against Preservation Injury," Liver Transplantation, Vol. 10, 2004, pp. 1514-1523.

[14] R. Lopez-Andujar, S. Deusa, E. Montalva, et al., "Comparative Prospective Study of Two Liver Graft Preservation Solutions: University of Wisconsin and Celsior," Liver Transplantation, Vol. 15, No. 12, 2009, pp. 1709. 1717. doi:10.1002/1t.21945

[15] U. Maggi, L. Caccamo, S. Gatti, et al., "Celsior Solution and Clinical Liver Transplantation," Transplantation Proceedings, Vol. 32, No. 1, 2000, pp. 36-37. doi:10.1016/S0041-1345(99)00866-0

[16] J. C. Meneu Diaz, E. Vicente, J. Nuno, et al., "Prospective Comparative Study of the Efficacy of Celsior Solution for Preservation in Clinical Liver Transplant," Transplantation Proceedings, Vol. 34, No. 1, 2002, p. 49.

[17] P. Michel, R. Vial, C. Rodriguez and R. Ferrera, "A Comparative Study of the Most Widely Used Solutions for Cardiac Graft Preservation during Hypothermia," The Journal of Heart and Lung Transplantation: The Official Publication of the International Society for Heart Transplantation, Vol. 21, No. 9, 2002, pp. 1030-1039.

[18] B. Nardo, P. Beltempo, R. Bertelli, et al., "Comparison of Celsior and University of Wisconsin Solutions in Cold Preservation of Liver from Octogenarian Donors," Transplantation Proceedings, Vol. 36, No. 3, 2004, pp. 523524.

[19] P. Pedotti, M. Cardillo, P. Rigotti, et al., "A Comparative 
Prospective Study of Two Available Solutions for Kidney and Liver Preservation," Transplantation, Vol. 77, No. 10, 2004, pp. 1540-1545. doi:10.1097/01.TP.0000132278.00441.CF

[20] A. Knuth, H. Gabbert, W. Dippold, et al., "Biliary Adenocarcinoma. Characterisation of Three New Human Tumor Cell Lines," Journal of Hepatology, Vol. 1, No. 6, 1985, pp. 579-596. doi:10.1016/S0168-8278(85)80002-7

[21] N. Akamatsu, Y. Sugawara and D. Hashimoto, "Biliary Reconstruction, Its Complications and Management of Biliary Complications after Adult Liver Transplantation: A Systematic Review of the Incidence, Risk Factors and Outcome," Transplant International, Vol. 24, No. 4, 2011, pp. 379-392. doi:10.1111/j.1432-2277.2010.01202.x

[22] M. Gastaca, "Biliary Complications after Orthotopic Liver Transplantation: A Review of Incidence and Risk Factors," Transplantation Proceedings, Vol. 44, No. 6, 2012, pp. 1545-1549. doi:10.1016/j.transproceed.2012.05.008

[23] M. Scotte, B. Dousset, Y. Calmus, et al., "The Influence of Cold Ischemia Time on Biliary Complications Following Liver Transplantation," Journal of Hepatology, Vol. 21, No. 3, 1994, pp. 340-346. doi:10.1016/S0168-8278(05)80311-3

[24] M. L. DeOliveira, W. Jassem, R. Valente, et al., "Biliary Complications after Liver Transplantation Using Grafts from Donors after Cardiac Death: Results from a Matched Control Study in a Single Large Volume Center," Annals of Surgery, Vol. 254, No. 5, 2011, pp. 716-722.

[25] D. X. Cui, J. Q. Yin, W. X. Xu, et al., "Effect of Different Bile Duct Flush Solutions on Biliary Tract Preservation Injury of Donated Livers for Transplantation," Transplantation Proceedings, Vol. 42, No. 5, 2010, pp. 15761581. doi:10.1016/i.transproceed.2009.12.057

[26] L. Feng, N. Zhao, X. Yao, et al., "Histidine-TryptophanKetoglutarate Solution vs. University of Wisconsin Solution for Liver Transplantation: A Systematic Review," Liver Transplantation, Vol. 13, No. 8, 2007, pp. 11251136. doi:10.1002/1t.21208

[27] J. Erhard, R. Lange, R. Scherer, et al., "Comparison of Histidine-Tryptophan-Ketoglutarate (HTK) Solution versus University of Wisconsin (UW) Solution for Organ Preservation in Human Liver Transplantation. A Prospec- tive, Randomized Study," Transplant International, Vol. 7, No. 3, 1994, pp. 177-181.

[28] Z. A. Stewart, A. M. Cameron, A. L. Singer, R. A. Montgomery and D. L. Segev, "Histidine-Tryptophan-Ketoglutarate (HTK) Is Associated with Reduced Graft Survival in Deceased Donor Livers, Especially Those Donated after Cardiac Death," American Journal of Transplantation, Vol. 9, No. 2, 2009, pp. 286-293. doi:10.1111/j.1600-6143.2008.02478.x

[29] G. Testa, M. Malago, S. Nadalin, et al., "Histidine-Tryptophan-Ketoglutarate versus University of Wisconsin Solution in Living Donor Liver Transplantation: Results of a Prospective Study," Liver Transplantation, Vol. 9, No. 8, 2003, pp. 822-826. doi:10.1053/jlts.2003.50168

[30] X. N. Feng, X. Xu and S. S. Zheng, "Current Status and Perspective of Liver Preservation Solutions," Hepatobiliary and Pancreatic Diseases International, Vol. 5, No. 4, 2006, pp. 490-494.

[31] H. Janssen, P. H. Janssen and C. E. Broelsch, "Value of Energy Substrates in HTK and UW to Protect Human Liver Endothelial Cells against Ischemia and Reperfusion Injury," European Surgery Research, Vol. 36, No. 1, 2004, pp. 26-32. doi: $10.1159 / 000075071$

[32] C. Moench and G. Otto, "Ischemic Type Biliary Lesions in Histidine-Tryptophan-Ketoglutarate (HTK) Preserved Liver Grafts," International Journal of Artificial Organs, Vol. 29, No. 3, 2006, pp. 329-334.

[33] C. J. O'Connor, R. G. Wallace, K. Iwamoto, T. Taguchi and J. Sunamoto, "Bile Salt Damage of Egg Phosphatidylcholine Liposomes," Biochimica et Biophysica Acta, Vol. 817, No. 1, 1985, pp. 95-102.

[34] D. Komichi, S. Tazuma, T. Nishioka, et al., "Unique Inhibition of Bile Salt-Induced Apoptosis by Lecithins and Cytoprotective Bile Salts in Immortalized Mouse Cholangiocytes," Digestive Diseases and Sciences, Vol. 48, No. 12, 2003, pp. 2315-2322. doi:10.1023/B:DDAS.0000007869.67105.27

[35] H. Hoekstra, R. J. Porte, Y. Tian, et al., "Bile Salt Toxicity Aggravates Cold Ischemic Injury of Bile Ducts after Liver Transplantation in Mdr2+/- Mice," Hepatology, Vol. 43, 2006, pp. 1022-1031. 